\title{
The use of penile prostheses in the management of priapism
}

\author{
Jonathan Moore ${ }^{1}$, Thomas F. Whelan', Gavin M. Langille ${ }^{2}$ \\ ${ }^{1}$ Department of Urology, Dalhousie University, Halifax, NS, Canada; ${ }^{2}$ Department of Urology, Dalhousie University, Saint John, NB, Canada \\ Contributions: (I) Conception and design: All authors; (II) Administrative support: None; (III) Provision of study materials or patients: None; (IV) \\ Collection and assembly of data: All authors; (V) Data analysis and interpretation: All authors; (VI) Manuscript writing: All authors; (VII) Final \\ approval of manuscript: All authors. \\ Correspondence to: Gavin M. Langille, MD, FRCSC. Department of Urology, Dalhousie University, 3DN Suite E, 400 University Avenue, Saint John, \\ New Brunswick, E2L-4L2, Canada. Email: gavin.langille@gmail.com.
}

\begin{abstract}
Priapism is a relatively uncommon condition that can result in erectile dysfunction (ED) and corporal fibrosis. Cases of prolonged priapism are particularly prone to ED, which arises when priapism is treatment refractory or had a delayed presentation. Due to the emergent nature of priapism, it behooves urologists to be familiar with all potential treatment modalities to minimize adverse outcomes. In this review paper, we aim to summarize the literature regarding the use of penile prosthesis (PP) implantation in the setting of ischemic priapism (IP). In some patients who present later or have prolonged initial treatment, early insertion of PP may be indicated.
\end{abstract}

Keywords: Priapism; penile prosthesis (PP); erectile dysfunction (ED)

Submitted Jan 30, 2017. Accepted for publication Apr 12, 2017.

doi: 10.21037/tau.2017.04.26

View this article at: http://dx.doi.org/10.21037/tau.2017.04.26

\section{Introduction}

The definition of priapism is a full or partial erection that persists beyond or occurs unrelated to sexual stimulation. The traditional cut-off is four hours or more in duration (1). Priapism is relatively rare, with an incidence of $0.5-0.9$ cases per 100,000 person years (1). These numbers are thought to be increasing related to the introduction of intercavernosal injections for erectile dysfunction (ED) (2).

Three subtypes of priapism exist: stuttering, nonischemic, and ischemic (1). Stuttering priapism refers to recurrent, painful and unwanted erections that happen more commonly in patients with sickle cell disease or those with a history of ischemic priapism (IP). Non-IP is also known as high flow priapism; unregulated cavernosal arterial inflow causes a semi-rigid, non-painful erection. It can be related to an arteriolar-sinusoidal fistula from prior trauma or iatrogenic causes. Management is expectant in most cases of high flow priapism, but some patients require arterial embolization or ligation of the fistula. Ischemic or low-flow priapism is characterized by the lack of arterial blood flow, which can be assessed by Doppler ultrasound or inferred from cavernosal blood gas measurements. Patients typically have a painful, rigid penis. There are many potential underlying etiologies for IP including medication induced, infection, neoplasm, metabolic disorders, hematologic, neurologic, and idiopathic.

\section{First line treatment of IP}

The treatment algorithm for IP involves a stepwise approach from corporal aspiration and saline irrigation, and if required injection of alpha agonists such as phenylephrine $(1,3)$. Cases refractory to these steps proceed to distal then proximal shunting procedures to establish flow between the corpus cavernosum and spongiosum. Lue et al. has hypothesised that the addition of upfront anticoagulation may improve outcomes for distal shunting. This may be due to improved blood flow across the shunt (4). Furthermore, proximal shunts may be less effective, again, because of a lack of sufficient blood flow $(5,6)$. There is overall little to no evidence to show superiority of one type of shunt over another. Currently the AUA and EAU both recommend a proceeding from a distal to a proximal shunt in the patient 
with IP.

Emergency management of IP is indicated due to the rapid evolution of irreversible changes in the erectile tissues (1). Within hours there is onset of edema. Progressive destruction of sinusoidal endothelial cells and thrombocyte adherence can be seen at 24 hours. By 48 hours thrombi form in the sinusoidal spaces. At that point, complete smooth muscle necrosis or transformation to fibroblast-like cells is nearly universally present (7). The natural history of IP helps explain the increasing rates ED as the duration of priapism increases. Once tissue necrosis occurs, alpha agonist agents can no longer influence smooth muscle contraction (8).

In cases of prolonged IP, there have been a number studies looking at the efficacy of shunt procedures. A series by Brant et al. (9) have shown success using an approach of distal, bilateral T-shunting and corporal snaking in 13 patients, even after 36 hours. Among the 11 patients who presented at least 1.5 days or 36 hours after presentation, $5(46 \%)$ had scores of 4 or 5 on the most clinically significant SHIM questions, numbers 2 and 3. The authors attribute the improved outcomes of their technique over standard distal shunting to the larger channel for drainage for the old, sludge-like blood in the corpora created by the tunnelling (9). Subsequent series, however, have been unable to replicate their results. In a series of 45 patients treated with T-shunt and corporal snake maneuver by Zacharakis et al. (10), rates of ED were high. Also, degree of ED was correlated with the duration of ischemia based on International Index of Erectile Function (IIEF-5) scores 6 months after treatment of the episode. Any grade of ED (IIEF-5 score less than 22) was seen in $100 \%$ men after 36 hours of IP and this advanced to severe ED (IIEF-5 less than 7) after 48 hours in all patients in their series. Additional, smaller series (11-13) of 3-12 patients demonstrated that none of the patients had spontaneous erectile function post-priapism when presenting greater than 36 hours post-onset. In one of the studies (11), however, the duration was significantly longer with a mean 75 hours. Only eight of the ten had resolution of the priapism and associated symptoms with the procedure in that same study. Comparisons between all the studies are hampered by the heterogeneity of the patients, small numbers, and, in the case of the final study, by a longer mean duration of priapism.

Patients with previous episodes of prolonged priapism have high rates of ED and corporal fibrosis. Some authors have concluded that penile prosthesis (PP) insertion is often required in this population to allow erections sufficiently rigid for penetration ED (10). European Urology Association guidelines (1) currently recommend that in cases of priapism that present after 36 hours resistant to first line treatments including shunting procedures, ED is inevitable. Immediate PP insertion is recommended to avoid the corporal fibrosis associated with later insertion. The AUA guidelines on priapism, last updated 2003, do not discuss the use of PP for refractory IP (3). They do, however, list $\mathrm{PP}$ as a last resort for stuttering priapism. The use of PP in refractory IP will be discussed below.

\section{Corporal fibrosis}

One of the main challenges for surgeons offering a PP for the post-priapism patient is corporal fibrosis, which leads to higher perioperative complication rates (14). During IP, corporal tissue can be replaced with a dense fibrotic scar $(8,15)$. Other etiologies associated with corporal fibrosis include Peyronie's disease, penile trauma, and infected penile implants (16). Distal fibrosis is more likely to occur in patients with a history of priapism while infection more often causes scar in the proximal corpora (15).

Multiple treatment options have been explored to address corporal fibrosis during PP insertion. The use of cavernotomes $(17,18)$, direct excisions of scar $(19)$, corporotomies with or without allografting (20-25) endoscopic excision (26,27), and "tissue expansion" with downsized implants (15) have been described. Complication rates for these procedures are reportedly significant. Intraoperative complications include urethral injuries and corporeal perforation (15). Late complications include infection, erosion, mechanical failure, penile shortening, and autoinflation (28). In one review, corporotomies with or without grafting resulted in a $30 \%$ early complication rate, and $50-65 \%$ of patients have late complications (16). Despite this, patient reported outcomes show $71-100 \%$ (29) of patients being satisfied with results. Primary patient complaints are of penile shortening, altered sensation, pain, decreased glanular engorgement and poor cosmetic result (29).

In a series by Durazi et al. (30), 17 patients had a PP placed 6-18 months after an episode of IP. Extensive corporal fibrosis was managed with sharp excision. There were two urethral injuries managed with primary closure. Patients who went to the OR before and after 1 year from the time of IP episode had surgical operative times of 30-60 and $60-180 \mathrm{~min}$, respectively. There were no late complications or reoperations and 16 of 17 patients 


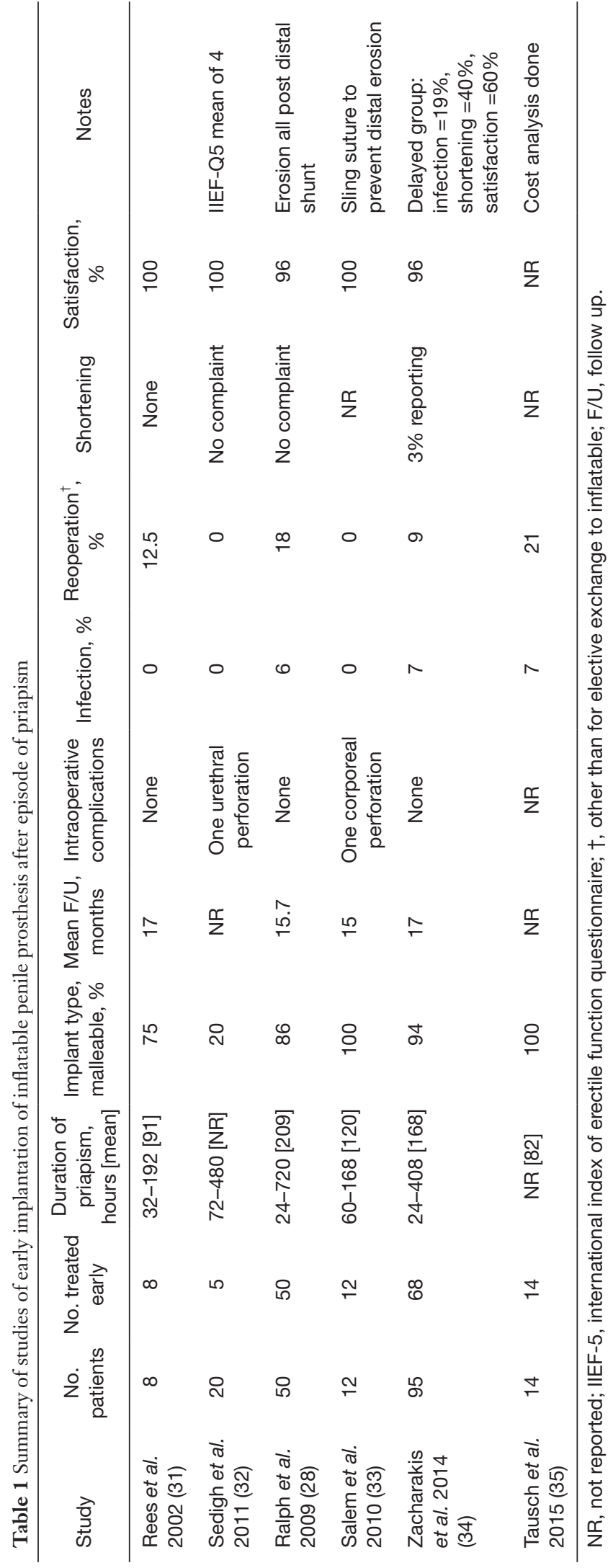

were sexually active on follow-up. One group suggests using the smaller, narrower inflatable cylinders as tissue expanders which can be upsized 8-12 months later. Thirty-seven patients with corporal fibrosis received Mentor Narrow Base or AMS CXR/M (American Medical Systems Minnetonka, MN, USA), 8 of which were post-priapism (15). There was a $54 \%$ chance of dilator perforation at time of surgery and $30 \%$ had impending cylinder erosion during the second stage surgery. The post IP group was able to tolerate upsizing to wider cylinders, but no upsizing of implant length was possible. In contrast the group with fibrosis not due to IP had both longer and wider cylinders inserted at the second stage surgery. These findings highlight the potential for irreversible loss of length for patients with corporal fibrosis post IP.

\section{Timing of insertion}

There is a growing body of research looking at early insertion of PP after an episode of IP (28,31-34). In published studies, the timing of an early insertion ranges from 24-720 hours after onset of priapism (28,31-34). Suggested benefits include decreased penile shortening $(28,31,32)$, decreased complication rates (34), easier operative technique $(30,31,33,34)$, shorter operative time (30), and decreased cost (35). Many of the proposed advantages stem from the avoidance of severe corporal fibrosis. In the setting of a patient with severe baseline ED who presents with priapism, an early implant may offer a single solution for both issues (31). A summary of outcomes and complications for early insertion of PP after IP are listed in Table 1. Studies are limited to a single cohort study and multiple case series.

In series that used early insertion of PP, data on penile length is poorly reported. Rees et al. (31) describes a subjective maintenance of penile length with no quantitative or qualitative data. In a non-randomized, observational study by Zacharakis et al. (34) 95 men had PP placed after IP. 68 received PP in the first 7 days after IP, the rest of the group received an implant 5 months post IP. Patient reported outcome of low sexual satisfaction were $40 \%$ and $3 \%$ for the delayed and early operative group, respectively $(\mathrm{P}<0.001)$. Sedigh et al. report the outcomes of 20 patients with IP; five patients ultimately underwent early PP placement (32). The duration of priapism was 3-20 days. A mean decrease in penile length of $3.5 \mathrm{~cm}$ was seen in those who did not undergo PP placement, versus no decrease in the PP group. 
The types of complications observed in the early insertion groups are similar to those in the late insertion series (28,31-35). The most common early complication was urethral perforation (0-20\%). When encountered, this was managed with primary closure at the time of the insertion $(32,33)$. The indications for reoperation after early insertion were infection $[6-7 \%(28,34)]$, erosion $[0-6 \%$ $(28,34)]$, short cylinders [4\% (28)], autoinflation [2\% (28)], and residual curvature $[1-2 \%(28,34)]$. In a series where 43 patients received a malleable device initially, six elected re-operation to exchange for an inflatable PP (28). Rates of revision were significantly less in patients who had early versus delayed PP placement [9\% vs. $27 \%, \mathrm{P}<0.03$ (34)]. After distal shunting is performed, consideration for delaying PP placement is warranted due to concern over the risk of infection (34). In studies the by Ralph et al. (28) and Zacharakis et al. (34), only $34 \%$ and $38 \%$ of IP patients had a shunt prior to PP placement, respectively. They found that all patients who presented with infection either had a previous T-shunt $(28,34)$ or glans erosion $(34)$. The duration of delay for PP placement after unsuccessful shunt surgery is suggested to be at least a "few days" to allow tissue healing, but no longer than 2 weeks to ensure ease of dilation prior to the onset of fibrosis (34). Ralph et al. suggest that bruising and edema is a contraindication to insertion of a three-piece inflatable prosthesis, and recommend malleable prosthesis in this setting (28). The finding of residual curvature appears to be correlated with inflatable devices that have not been cycled by the patient adequately $(28,34)$. If inflatable prostheses are used, early and frequent cycling is suggested to prevent curvature and contracture due to formation of a fibrotic capsule (28).

Salem et al. (33) developed a technique to reduce the rate of distal erosion in patients undergoing malleable PP insertion who have had a previous distal shunt for IP. Their hypothesis is that distal shunts and especially El-Ghorab shunts, weaken the distal corpora and put the patient at risk of distal erosion $(28,33)$. Their approach is to use a sling-like suture to stop distal device migration and erosion through the weakened tip after the distal shunt procedure. This is in place of the alternative approach, cited by the authors, of using a shorter cylinder that does not press on the shunt site, but may need to be exchanged for an appropriately sized one at a later date. Using a heavy, nonabsorbable polypropylene suture, a tacking stitch is made through the corporotomy and the cylinder core. There was no distal erosion seen in their study of 12 patients. One patient did have a corporal perforation, but it was during the use of the Brooks dilators at the time of the original surgery.

Direct data on the technical difficulty of the insertion is mostly subjective. The early surgery is described in the literature as being an "easy dilation" $(33,34)$ resulting in "rapid detumescence" (31) with "easy insertion" $(31,32)$ of cylinders. Ralph et al. (28) state that the "...operation was easily performed and usually took $<60$ min." Surgical time was explored in one study in a more delayed setting. A series of 17 ED patients with delayed PP placement 6-18 months after the IP episode describes difficult PP placement secondary to fibrosis (30). A malleable prosthesis (AMS 650, American Medical Systems Minnetonka, MN, USA) was placed in 11 patients, 2-piece Ambicor inflatable in four patients, and 3-piece $700 \mathrm{CX}$ in two patients. In that study, the difficulty of PP placement increased for patients undergoing surgery after 12 months post IP episode; the overall surgical time increased from $30-60$ to $60-180 \mathrm{~min}$ before and after 12 months, respectively.

Patient satisfaction remains high after early insertion and ranges from $96-100 \%$ (28,31-34). Most reports base satisfaction on achievement of sexual intercourse alone $(28,31,33,34)$. Sedigh et al. (32) reported a mean score of 4 out of 5 on question 5 of the IIEF- 5 questionnaire, representing achievement of satisfactory sexual intercourse more than half of the time. Zacharakis et al. compared the sexual satisfaction of early and delayed insertion groups (34). Satisfaction was $90 \%$ vs. $60 \%$ in the early versus delayed group, respectively $(\mathrm{P}<0.001)$, with most the dissatisfaction arising from penile shortening.

Cost-effectiveness of early PP insertion in the setting of IP was explored in a study by Tausch $e t$ al. (35). Health care related costs were calculated for 14 men with refractory priapism who eventually received a PP. Average cost of care prior to PP insertion was $\$ 83,818$ USD, including a mean of 4 ER visits, 2 hospital admissions, 1.5 shunts performed, 5 irrigation and phenylephrine injection procedures, and 6 days in hospital. Time to insertion of the device was 82 hours, on average. The cost of the implant itself was $\$ 3,850$ USD. Patients were discharged within 24 hours after PP placement. Potential cost savings may exist if early PP implantation occurs, especially if it prevents potentially ineffective procedures in those who present later than 36-48 hours after onset. Missing from their cost analysis is the delayed, significant cost of an eventual elective replacement of the malleable for inflatable prosthesis that some men may request. The authors note that their facility carries a stock of malleable prostheses to allow after 


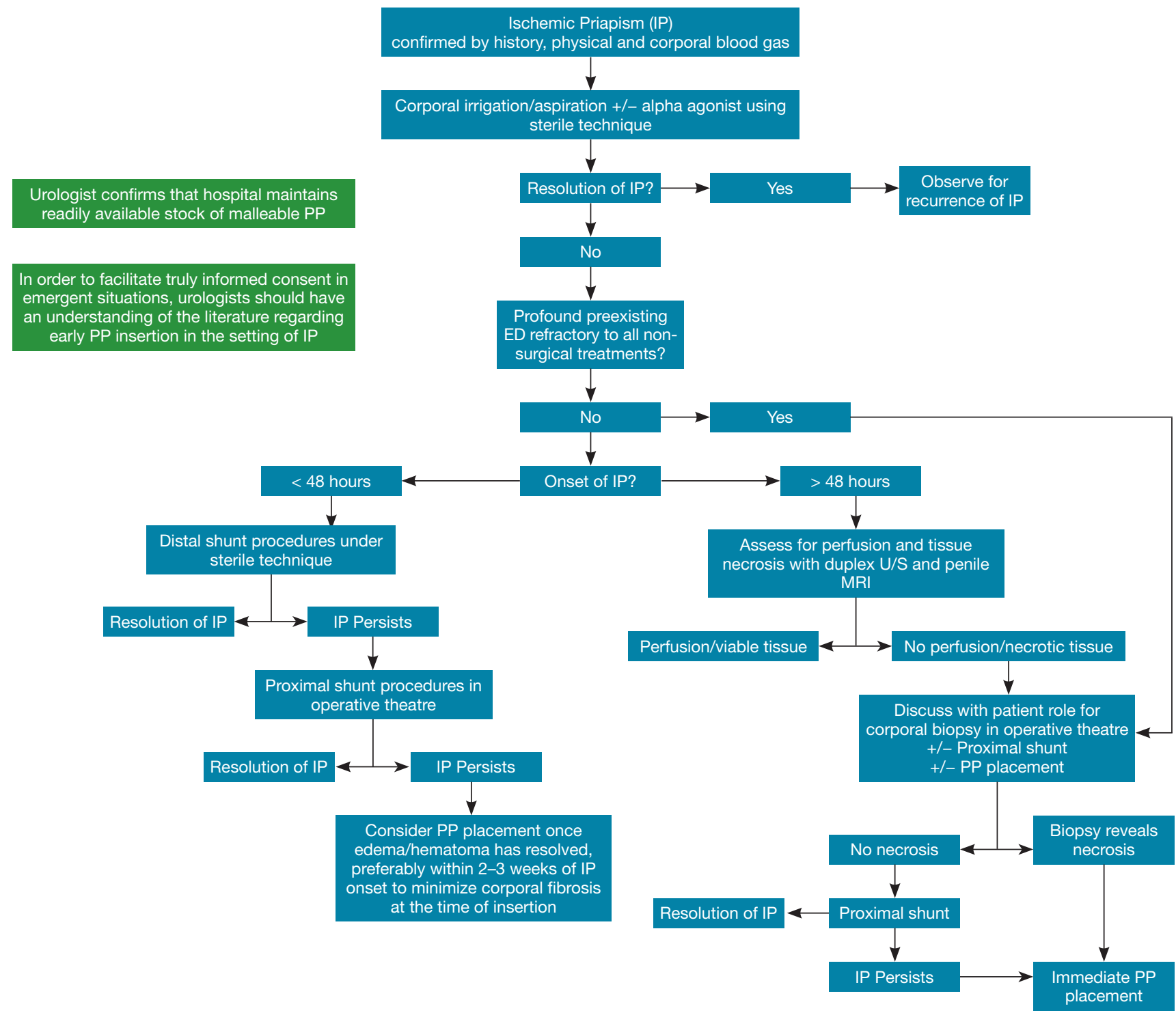

Figure 1 Treatment algorithm for the management of ischemic priapism (IP) with a focus on the role of early penile prosthesis (PP) placement. The evidence for early PP placement is limited; relying heavily on case series and on expert opinion. When counselling parents regarding treatment options in the setting of IP, conversations must be tailored to include patient factors including goals of care and individual medical considerations.

hours or weekend implantation without having to contact sales representatives or manufacturers. Levey et al. (36) have suggested that financial coverage and truly informed consent may be barriers to early insertion.

Zacharakis et al. have suggested an accelerated algorithm for PP placement. (34) If onset of priapism is less than 48 hours, an attempt at shunting is recommended with concurrent smooth muscle biopsy. An unsuccessful shunt or presence of smooth muscle necrosis triggers PP insertion.
All patients presenting after 72 hours are recommended for early PP under their proposal. Those within the 48-72 hour window can have an MRI and penile duplex ultrasound assess perfusion. Lack of perfusion triggers PP insertion while distal shunting is suggested for those with perfusion.

We present the treatment algorithm for management of IP used at our institution (Figure 1). While this algorithm attempts to incorporate the available literature and guidelines regarding early PP placement, much of it relies 
on expert opinion. The successful of IP treatment relies on early recognition and treatment with first line therapies to maximize the ED outcomes and avoids the need for an invasive and permanent procedure in the form of PP. This algorithm serves to remind urologists that in certain instances, early PP placement should be discussed with the patient. The presence of pre-existing severe ED, evidence of smooth muscle necrosis, or priapism refractory to all other treatments should be considered for PP placement. Distal corporoglanular shunting procedures (once considered a mainstay of treatment for all IP patients) might be reconsidered in delayed presentations of IP, as these procedures can increase the risk of erosion and infection if subsequent PP insertion is performed. The definition of delayed priapism-after which ED is inevitable-is controversial and varies among studies. While most patients would have significant ED after 36 hours (10), some may still maintain function (9). It seems universal that patients presenting after 48 hours will have no erectile function (10). We therefore propose that if a patient presents greater than 48 hours after onset and is willing to have PP placed after appropriate counselling, that the distal shunt be omitted for those reasons. In addition, based on the information we know on the histological changes (7) and outcomes for delayed distal shunting $(9,11,12)$, ED inevitable for these patients. For that reason, early PP insertion could avoid the complications associated with a delayed insertion secondary to corporal fibrosis. All procedures such as irrigation and shunting should be performed under sterile technique with the understanding that these patients may ultimately require PP placement. We theorize that proximal shunting (such as the Quackels or Sacher procedures) performed in the operative theater under sterile technique would have less risk of infection and erosion with subsequent $\mathrm{PP}$ insertion. Urologists must be aware of the limitations within the existing literature on this topic due to the emergent nature of IP and the possibility of medical-legal implications of poor outcomes. Clinicians must use clinically sound judgment and individualize treatments for patients with IP; no single treatment algorithm can definitively account for all medical scenarios.

\section{Conclusions}

IP lasting longer than 48 hours usually results in severe corporal fibrosis, ED, and penile shortening. Implantation of a PP is often required to re-establish erectile function for these patients. Delayed PP insertion presents a difficult surgical challenge with worse patient outcomes due to significant corporal fibrosis. Patients with IP who fail less invasive management options, or with delayed IP presentation, should be counselled regarding the option of early PP implantation within 2 weeks of IP onset.

\section{Acknowledgements}

None.

\section{Footnote}

Conflicts of Interest: The authors have no conflicts of interest to declare.

\section{References}

1. Salonia A, Eardley I, Giuliano F, et al. European Association of Urology guidelines on priapism. Eur Urol 2014;65:480-9.

2. Broderick GA, Kadioglu A, Bivalacqua TJ, et al. Priapism: pathogenesis, epidemiology, and management. J Sex Med 2010;7:476-500.

3. Montague DK, Jarow J, Broderick GA, et al. American Urological Association guideline on the management of priapism. J Urol 2003;170:1318-24.

4. Lue TF. Shunting for prolonged ischemic priapism: a 50year mistake? Transl Androl Urol 2014;3:AB06.

5. Garcia M, Porten S, Lue TF. Commentary on refractory ischemic priapism. Transl Androl Urol 2012;1:61-5.

6. Kovac JR, Mak SK, Garcia MM, et al. A pathophysiologybased approach to the management of early priapism. Asian J Androl 2013;15:20-6.

7. Spycher MA, Hauri D. The ultrastructure of the erectile tissue in priapism. J Urol 1986;135:142-7.

8. Tausch TJ, Mauck R, Zhao LC, et al. Penile prosthesis insertion for acute priapism. Urol Clin North Am 2013;40:421-5.

9. Brant WO, Garcia MM, Bella AJ, et al. T-shaped shunt and intracavernous tunneling for prolonged ischemic priapism. J Urol 2009;181:1699-705.

10. Zacharakis E, Raheem AA, Freeman A, et al. The efficacy of the T-shunt procedure and intracavernous tunneling (snake maneuver) for refractory ischemic priapism. J Urol 2014;191:164-8.

11. Segal RL, Readal N, Pierorazio PM, et al. Corporal Burnett "Snake" surgical maneuver for the treatment of ischemic priapism: long-term followup. J Urol 
2013;189:1025-9.

12. Burnett AL, Pierorazio PM. Corporal "snake" maneuver: corporoglanular shunt surgical modification for ischemic priapism. J Sex Med 2009;6:1171-6.

13. Lian W, Lv J, Cui W, et al. Al-Ghorab Shunt plus intracavernous tunneling for prolonged ischemic priapism. J Androl 2010;31:466-71.

14. Martínez-Salamanca JI, Mueller A, Moncada I, et al. Penile prosthesis surgery in patients with corporal fibrosis: a state of the art review. J Sex Med 2011;8:1880-9.

15. Wilson SK, Delk JR 2nd, Mulcahy JJ, et al. Upsizing of inflatable penile implant cylinders in patients with corporal fibrosis. J Sex Med 2006;3:736-42.

16. Yafi FA, Sangkum P, McCaslin IR, et al. Strategies for penile prosthesis placement in Peyronie's disease and corporal fibrosis. Curr Urol Rep 2015;16:21.

17. Mooreville M, Adrian S, Delk JR 2nd, et al. Implantation of inflatable penile prosthesis in patients with severe corporeal fibrosis: introduction of a new penile cavernotome. J Urol 1999;162:2054-7.

18. Rosselló Barbará M, Carrión H. Cavernotomy. Arch Esp Urol 1991;44:185-6.

19. Montague DK, Angermeier KW. Corporeal excavation: new technique for penile prosthesis implantation in men with severe corporeal fibrosis. Urology 2006;67:1072-5.

20. Sansalone S, Garaffa G, Djinovic R, et al. Simultaneous total corporal reconstruction and implantation of a penile prosthesis in patients with erectile dysfunction and severe fibrosis of the corpora cavernosa. J Sex Med 2012;9:1937-44.

21. Lopes EJ, Kuwano AY, Guimaraes AN, et al. Corporoplasty using bovine pericardium grafts in complex penile prosthesis implantation surgery. Int Braz J Urol 2009;35:49-53; discussion 53-5.

22. Palese MA, Burnett AL. Corporoplasty using pericardium allograft (tutoplast) with complex penile prosthesis surgery. Urology 2001;58:1049-52.

23. George VK, Shah GS, Mills R, et al. The management of extensive penile fibrosis: a new technique of 'minimal scartissue excision'. Br J Urol 1996;77:282-4.

24. Herschorn S, Ordorica RC. Penile prosthesis insertion with corporeal reconstruction with synthetic vascular graft material. J Urol 1995;154:80-4.

Cite this article as: Moore J, Whelan TF, Langille GM. The use of penile prostheses in the management of priapism. Transl Androl Urol 2017;6(Suppl 5):S797-S803. doi: 10.21037/ tau.2017.04.26
25. Knoll LD, Furlow WL. Corporeal reconstruction and prosthetic implantation for impotence associated with non-dilatable corporeal cavernosal fibrosis. Acta Urol Belg 1992;60:15-25.

26. Shaeer O, Shaeer A. Corporoscopic excavation of the fibrosed corpora cavernosa for penile prosethesis implantation: optical corporotomy and trans-corporeal resection, Shaeer's technique. J Sex Med 2007;4:218-25.

27. Park JK, Kim HJ, Kang MH, et al. Implantation of penile prosthesis in a patient with severe corporeal fibrosis induced by cavernosal injection therapy. Int J Impot Res 2002;14:545-6.

28. Ralph DJ, Garaffa G, Muneer A, et al. The immediate insertion of a penile prosthesis for acute ischaemic priapism. Eur Urol 2009;56:1033-8.

29. Trost L, Patil M, Kramer A. Critical Appraisal and Review of Management Strategies for Severe Fibrosis During Penile Implant Surgery. J Sex Med 2015;12 Suppl 7:439-47.

30. Durazi MH, Jalal AA. Penile prosthesis implantation for treatment of postpriapism erectile dysfunction. Urol J 2008;5:115-9.

31. Rees RW, Kalsi J, Minhas S, et al. The management of low-flow priapism with the immediate insertion of a penile prosthesis. BJU Int 2002;90:893-7.

32. Sedigh O, Rolle L, Negro CL, et al. Early insertion of inflatable prosthesis for intractable ischemic priapism: our experience and review of the literature. Int J Impot Res 2011;23:158-64.

33. Salem EA, El Aasser O. Management of ischemic priapism by penile prosthesis insertion: prevention of distal erosion. J Urol 2010;183:2300-3.

34. Zacharakis E, Garaffa G, Raheem AA, et al. Penile prosthesis insertion in patients with refractory ischaemic priapism: early vs delayed implantation. BJU Int 2014;114:576-81.

35. Tausch TJ, Zhao LC, Morey AF, et al. Malleable penile prosthesis is a cost-effective treatment for refractory ischemic priapism. J Sex Med 2015;12:824-6.

36. Levey HR, Segal RL, Bivalacqua TJ. Management of priapism: an update for clinicians. Ther Adv Urol 2014;6:230-44. 